\title{
Accuracy Assessment of \\ a Variety of GPS Data Processing, Online Services and Software
}

\begin{abstract}
The processing of GPS observations in precise positioning is complex and requires professional surveyors since it must be carried out after each static measurement. In GPS network adjustment, the obtaining of the correct coordinates of the determined point is possible after determining the components of GPS vectors and aligning the networks of these vectors, while PPP requires the availability of precise products for the reference satellites orbits and clock. For that reason, surveyors can take advantage of free online GPS data processing. In this paper, the authors compare the results obtained from different sources of free online GPS data processing (AUSPOS, OPUS, CenterPoint RTX, APPS, MagicGNSS, CSRS-PPP, GAPS, and SCOUT) in terms of their accuracy, availability, and operation. This is then compared with free GPS processing software (gLAB and RTKLIB), and finally with commercial software (TBC Trimble Business Center). The results show that online processing services are more accurate than offline processing software, which indicates the strength of their algorithms and processes. The CSRS-PPP online service had the best results. The difference between the relative solution of AUSPOS and OPUS, and CSRS-PPP is insignificant.
\end{abstract}

Keywords: online GPS, relative solution, PPP, accuracy assessment, software comparison

Received: 17 December 2020; accepted: 14 June 2021

(C) 2021 Authors. This is an open access publication, which can be used, distributed and reproduced in any medium according to the Creative Commons CC-BY 4.0 License.

1 Civil Engineering Department, University of Technology - Iraq, email: 40278@uotechnology.edu.iq, ORCID ID: https://orcid.org/0000-0002-8904-0097

2 Civil Engineering Department, University of Technology - Iraq, email: 40111@uotechnology.edu.iq, ORCID ID: https://orcid.org/0000-0002-5838-3687

3 Civil Engineering Department, University of Technology - Iraq, email: 40316@uotechnology.edu.iq, ORCID ID: https://orcid.org/0000-0002-1026-8866 


\section{Introduction}

The majority of the users of GPS data employ it effectively in different engineering and geodetic projects as an alternate solution to traditional surveying methods [1]. In order to achieve a high degree of precision in terms of location, the use of differential positioning techniques is required in field measurements and in the processing of GPS data using License postprocessing or Commercial software employed by GPS experts [2]. This software required user training and experience [1]. As an alternative option, a number of agencies have therefore established user-friendly web-based services to calculate high accuracy positioning [3]. During the last several years, some research centers, universities, and organizations have adopted new methods for GPS data analysis and processing in order to achieve high-precision GPS locations [4-10]. One of those methods is the online web-based GNSS analysis tool, that calculates user coordinates to a precision of centimeters [11] is the Online Positioning User Service (OPUS) which is controlled by the National Geodetic Survey (NGS) [12], and AUSPOS which is the online static GPS position program of Geoscience Australia [13]. A computer with Internet access and a web browser are the only condition to use these programs, which are usually offered free of charge and for unlimited use [2].

There have been a number of scientific publications in recent years that have discussed various features of these services. Abd-Elazeem et al. [14] assessed the CSRS-PPP online processing service for mapping applications, the results concluded that the CSRS-PPP produces a horizontal error of a few decimeters. Ocalan [15] assessed the accuracy for the observation duration of 3-hours at different online services with the commercial processing software TopconTools v8.2 in a forest environment, the results give effective solutions. Kong et al. [16] analyzed the accuracy of the AUSPOS and CSRS-PPP using ten permanent GPS sites for the NGII (National Geographic Information Institute), the processing results coordinates are compared with published NGII. El Shouny and Miky [17] assessed the accuracy of several relative and PPP online services, and recommended that to achieve high accurate processing results, the observation time should be more than two hours. Ghoddousi-Fard and Dare [18] submitted a different set of RINEX observation files varying in locations and times to the online services, the results illustrate that for ten hours observation duration by dual-frequency geodetic receivers, GPS users can expect reliable online processing results anywhere in the world.

Surveyors can use online raw GPS data processing services to save time and money [19]. The motivation behind this paper is an evaluation of a variety of GPS data processing online services and software in terms of their precision, availability, and facility. The results were acquired from the free online GPS data processing services (AUSPOS, OPUS, CenterPoint RTX, APPS, MagicGNSS, CSRS-PPP, GAPS, and SCOUT) before being compared with each other and then with free GPS processing software (gLAB and RTKLIB) and commercial software (TBC Trimble 
Business Center). To accomplish this task, five CORS stations were distributed in different topographic regions in Iraq, and their coordinates were used to evaluate the accuracy of the online services and the software.

\section{Materials and Methods}

In recent years, several institutions have developed rigorous online processing services and GPS software to allow GPS operators to deliver free GPS processing solutions. GPS operators send the RINAX file to the online system in RINEX format and the coordinate location of the GPS receiver is returned in minutes or within a short time. Table 1 outlines a comparison of these services and software.

To assess the services and the software, raw GNSS observation data for 15 days (1.04.2019-15.04.2019) for the GNSS network of five CORS stations (ISBA, ISER, ISKU, ISNA, ZAXO) located in Iraq, Figure 1 are processed using all the services and the software in Table 1. The station coordinates are well known and can be founded on the NGS website, the method of the accuracy analysis depending on the differences in the coordinates between reference station coordinates and the estimated station coordinates from the online processing or the software.

Table 1. Online GPS processing services and software

\begin{tabular}{|l|l|l|l|l||}
\hline $\begin{array}{l}\text { Service or } \\
\text { software }\end{array}$ & $\begin{array}{l}\text { Post-processing } \\
\text { mode }\end{array}$ & \multicolumn{1}{|c|}{ Website } & \multicolumn{1}{|c|}{ Organization } & \multicolumn{1}{|c|}{$\begin{array}{c}\text { Ref. } \\
\text { frame }\end{array}$} \\
\hline \hline APPS & $\begin{array}{l}\text { PPP (static or } \\
\text { kinematic) }\end{array}$ & https://pppx.gdgps.net/submitx & $\begin{array}{l}\text { NASA - Jet Propul- } \\
\text { sion Laboratory (JPL) }\end{array}$ & ITRF2014 \\
\hline MagicGNSS & $\begin{array}{l}\text { PPP (static or } \\
\text { kinematic) }\end{array}$ & https://magicgnss.gmv.com/ppp/ & $\begin{array}{l}\text { GMV Innovating } \\
\text { Solutions }\end{array}$ & ITRF2014 \\
\hline CSRS-PPP & - & $\begin{array}{l}\text { https://webapp.geod.nrcan.gc.ca/ } \\
\text { geod/tools-outils/ppp.php }\end{array}$ & $\begin{array}{l}\text { Natural Resources } \\
\text { Canada }\end{array}$ & ITRF2014 \\
\hline $\begin{array}{l}\text { CenterPoint } \\
\text { RTX }\end{array}$ & PPP (static) & $\begin{array}{l}\text { https://trimblertx.com/ } \\
\text { UploadForm.aspx }\end{array}$ & Trimble & ITRF2014 \\
\hline GAPS & $\begin{array}{l}\text { PPP (static or } \\
\text { kinematic) }\end{array}$ & http://gaps.gge.unb.ca/ & $\begin{array}{l}\text { University of New } \\
\text { Brunswick }\end{array}$ & ITRF2014 \\
\hline AUSPOS & relative (static) & https://gnss.ga.gov.au/auspos & Geoscience Australia & ITRF2014 \\
\hline OPUS & $\begin{array}{l}\text { relative (static or } \\
\text { rapid static) }\end{array}$ & https://geodesy.noaa.gov/OPUS/ & $\begin{array}{l}\text { National Geodetic } \\
\text { Survey }\end{array}$ & ITRF2014 \\
\hline SCOUT & relative (static) & http://sopac.ucsd.edu/scout.shtml & $\begin{array}{l}\text { University of Califor- } \\
\text { nia, San Diego }\end{array}$ & ITRF2008 \\
\hline gLAB & $\begin{array}{l}\text { SPP, PPP, SBAS, } \\
\text { DGNSS }\end{array}$ & $\begin{array}{l}\text { https://gage.upc.edu/ } \\
\text { glab-download/ }\end{array}$ & $\begin{array}{l}\text { European Space } \\
\text { Agency }\end{array}$ & WGS84 \\
\hline RTKLIB & $\begin{array}{l}\text { SPP, PPP, } \\
\text { DGNSS, relative }\end{array}$ & http://www.rtklib.com/ & Tohoku University & WGS84 \\
\hline TBC & $\begin{array}{l}\text { relative, network } \\
\text { adjustment }\end{array}$ & $\begin{array}{l}\text { Generally Delivered with GNSS } \\
\text { Trimble receivers }\end{array}$ & Trimble & WGS84 \\
\hline
\end{tabular}




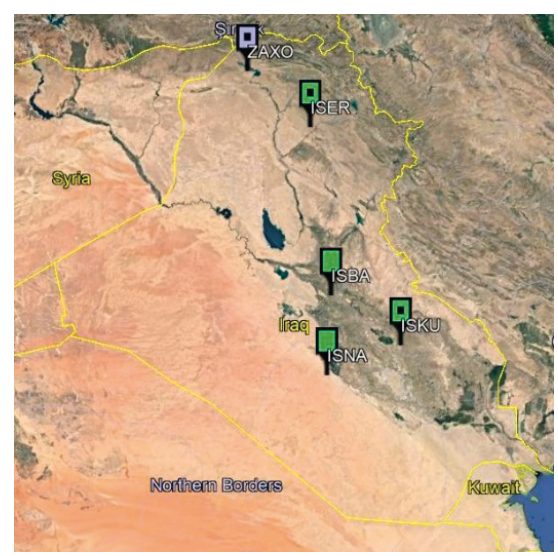

Fig. 1. Points locations in Iraq

\subsection{Online Precise Point Positioning (PPP) Services}

\section{APPS}

To calculate the location of the user GPS receivers, if they are static, kinematic in the air, or on the ground, APPS supports GPS observation files from the NASA Jet Propulsion Laboratory, applying the most sophisticated GPS processing technology. APPS uses:

- GPS orbit/clock errors from the GDGPS Program of JPL in real-time,

- correct GPS clock and orbit errors weekly and daily from JPL,

- JPL's software of GIPSY-OASIS used for GPS measurement post-processing.

The following upload choices are provided by APPS for the observation file:

- For quick processing, manually via the website.

- Users can email APPS and define the type of processing required.

- The user can upload and automatically download GPS calculation files through a particular area in the APPS Secure FTP server [11].

\section{MagicGNSS}

As part of its 25 years of professional experience, the magicGNSS System integrates state-of-the-art GMV GNSS algorithms. The following facilities are provided through magicGNSS' web service:

- Determination of clock and precise orbit for multi-constellation.

- Double and single-frequency multi-constellation system Precise Point Positioning (PPP).

- Long-term ephemeris products for multi-constellation to provide predictions and high-precision GNSS orbit and clock for A-GNSS projects.

- Station control and monitoring program that allows for real-time monitoring and observation by predefined KPI of the specified network of reference stations [20]. 


\section{CSRS-PPP}

The free online GNSS data post-processing program allows users to determine a higher precision of their raw observational data. CSRS-PPP utilizes accurate GNSS orbit ephemerides to generate accurate coordinates with a constant "absolute" precision, despite where GNSS users on the world, regardless of how close GNSS users are to the known base stations. RINEX observation data files can be sent from GNSS users throughout the internet from single or dual-frequency GNSS receivers run on a kinematic or a static observation method and the final coordinates will be in International Terrestrial Reference Frame (ITRF) and the Canadian Spatial Reference System [19, 21].

\section{CenterPoint RTX}

In mid-2011, CenterPoint RTX was launched to provide precise centimeter locations for static and/or kinematic applications in real-time. The RTX solutions are internationally accessible via the website it can be adopted for real-time applications for Trimble users. The Trimble GPS company also provides an open web platform for post-processing service [3]. With its great precision, high performance, simple accessibility, and fast integration, Trimble CenterPoint RTX has been well known by users in precision agriculture since it was first launched. Infrastructure and mapping tools Trimble RTX-based positioning systems have been also active since 2012 [22].

\section{GAPS}

GAPS is a positioning and data analysis online software (using standard PPP). The code structures and algorithms used in GAPS are GPS PPP standard solutions with a number of significant and exceptional differences. GAPS gives GPS users precise satellite positioning in the kinematic and static method of observation with the use of a single GNSS receiver. It can achieve centimeters and decimeters, in a reasonable convergence time in static method and in a kinematic method, can be obtained using specific orbit and clock products given by sources such as the Natural Resources Canada (NRCan) and International GNS Service(IGS) [5, 23].

\subsection{Online Relative Solution Services}

\section{Australia's Online Static GPS (AUSPOS)}

AUSPOS is the online static GPS position program of Geoscience Australia, which offers a simple web interface and links for GPS operators to the processing program. AUSPOS has been widely used as an online means for the online preprocessing of raw GPS data in the field of geomatics engineering, geography, geodesy, surveying, geophysics, hydrography, forestry, electronics, military, and other fields since it was founded in 2001. However, static raw GPS data recorded from anywhere 
in the world can be analyzed using double frequency GPS instruments for at minimum one hour (strongly advised 2 or even more hours) while kinematic GPS raw data can not be preprocessed with this online program. When the RINAX raw data file is sent to the web-server, it is analyzed in accordance with the closest stations of the APREF (Asia-Pacific Reference Frame) and GNSS (IGS) International Service, which are known to be reference points for the operation utilizing correct orbit details from IGS to retrieve the data. The IGS14 antenna phase center variance model is implemented by AUSPOS software [24].

\section{Online Positioning User Service (OPUS)}

In order to give GPS users a free link to the National Spatial Reference System (NSRS), an online positioning user service (OPUS) is controlled by the National Geodetic Survey (NGS). OPUS enables GPS users to upload their GPS raw data files to NGS, where the information is stored and the NGS algorithm is used to determine the user location. Every uploaded data file will be analyzed based on 3 near CORS stations. The station locations may not be closest to the user position, however, they are identified by distance, the number of observations, consistency of the location, etc. The processed GPS data location is notified via email both at ITRF and at northern and east UTM Coordinates.

OPUS is totally automated and therefore only requires a minimum of user details such as:

- the mailing address to which the results will be sent,

- the GPS record raw data to be analyzed,

- the category of GPS antenna for this GPS raw data file,

- height above monument or point where are locating the antenna reference point (ARP),

- the coding of the state plane is an option if the user wants the coordinate in the state plane north and east.

As an option, the GPS users can choose up to three close base stations for the user solution [25].

\section{SCOUT}

The Scripps Orbit \& Permanent Array Center is based at La Jolla, California University San Diego (UCSD). The main function of SOPAC is to experiment and enable high accuracy geodetical and geophysical observations through Global Navigation Satellite Systems (GNSS), such as GPS, especially for earthquake threat analysis, plate tectonic movement, boundary plate deformation, and meteorology. Many web services, including SCOUT (ITRF data generator from RINEX data), are easily accessible on the SOPAC homepage. By sending a RINEX GPS observation file on a specific date, the Scripps Coordinate Update Tool (SCOUT) can be used to estimate mean site coordinates [6]. 


\subsection{Free Online GNSS Processing Software}

\section{gLAB}

gLAB, an integrated multifunctional educational data collection and assessment program, is the computer software suite created by the European Space Agency (ESA) Contract of the Astronomy and Geomatics Research Group (GAGE) at the Universitat Politecnica de Catalunya (UPC). gLAB accurately models the carrier phases and pseudorange GNSS measurements in a centimeter degree, which provides a precise point positioning and stand-alone GPS positioning. Each contributor to error can be evaluated individually, which in turn offers important educational advantages. gLAB deals with a number of default file types such as SP3, RINEX-3.00, ANTEX, and SINEX, etc. In fact, GPS, Galileo, and GLONASS features are included, enabling actual multi-constellation technology to carry out certain analyses of data [26]. gLAB GUI has four postprocessing templates: Single Point Positioning (SPP), Precise Point Positioning (PPP), Space Based Augmentation System (SBAS), Differential Global Navigation Satellite System (DGNSS).

\section{RTKLIB}

RTKLIB is a free software package for GNSS (Global Navigation Satellite System) and precise point positioning. RTKLIB is composed of a small program collection and some programs using the database. RTKLIB has the following characteristics:

- The algorithms provide typical and precise positioning using: GLONASS, GPS, Galileo, BeiDou, QZSS, and SBAS.

- It supports different GNSS positioning methods for both post-processing and real-time.

- It supports various regular GNSS file types and protocols.

- It accepts proprietary code messages from many GNSS receivers.

- It enables outside communication

- It provides several libraries and API functions for processing GNSS [27].

\subsection{TBC Trimble Business Center}

Trimble Business Center is a Field to Finish survey CAD program used to help surveyors provide high-precision GNSS data and create CAD deliverables. As a Trimble GNSS data processing program, Trimble Geomatics Office was substituted by Trimble Business Center.

\section{Methodology}

In this research, 15 days of GNSS RINEX observations files from 1.04.2019 to 15.04.2019 for five CORS GNSS network stations in Iraq (ISBA, ISNA, ISER, ISKU, ZAXO) were used, the observation duration for each observation RINEX file was 24 hours, a total of 75 observation file were processed in each online services and software. After the finalization of the analysis of GPS observations, analytical revision 
to all of the GPS processed data to each file submitted or uploaded to the online services was investigated; AUSPOS, OPUS, CenterPoint RTX, APPS, MagicGNSS, CSRSPPP, GAPS, and SCOUT, are compared with offline software gLAB, RTKLIB, and TBC, the final results will be the differences between the estimated ENU coordinates of all the online and offline processing with the published coordinates of the CORS.

\section{Results and Discussion}

Various positioning methods are used in this research for different precise online applications, AUSPOS, OPUS, CenterPoint RTX, APPS, MagicGNSS, CSRSPPP, GAPS, and SCOUT, the results are processed and analyzed. In addition to the gLAB and RTKLIB and Trimble commercial software TBC, these tools are used professionally for the analysis of GNSS results. This research has also performed a comparative analysis using a large dataset of observations. All the online processing method provides their coordinates in International Terrestrial Reference Frame ITRF 2014, and the final coordinates of the processing of the gLAB, RTKLIB, and TBC are in WGS84 (G1762). Therefore, the coordinates must be transformed from WGS84 to ITRF-2014. Since the realizations of WGS84 equivalent to ITRF at a level of about $10-\mathrm{cm}$, consequently, there are no official transformation parameters between the two systems [28], so that the coordinates in WGS84 are considered as ITRF in this research.

At the time of this research, the GAPS website was working and we did not encounter any problems, but the authors did not receive any processing report email about the processing results for the points or if there is any problem with the data, even when using different browsers and different location and dates. For that reason, GAPS was not considered in the evaluation.

For the SCOUT online processing service, it has broad SOPAC GNSS control points distributed all over the world, one of the points used in this research (ISBA) is a SOPAC reference station, and their position estimates can be found in the archive of the solution which is easily accessible on the SOPAC homepage [29], for the four other points, after uploading the RINEX files to the FTP server of the SCOUT, the authors received the following error message:

“gamit solution failed, FATAL :210309:1012:34.0 MODEL/setup: SV antenna offsets for SVN G054 not found in antmod.dat".

According to Chen Chao Science Network blog [30], the SVN G054 corresponding to PRN18, and G054 was retired on the $23^{\text {rd }}$ of 2018, so that the PRN18 now corresponds to SVN34, so that in this research the authors only received the processing for point ISBA, and thus SCOUT will be removed from the evaluation.

For the rest of the processing methods, the results of the differences between reference coordinates and the estimated coordinates from different online services and software are illustrated in Figures 2-11. 

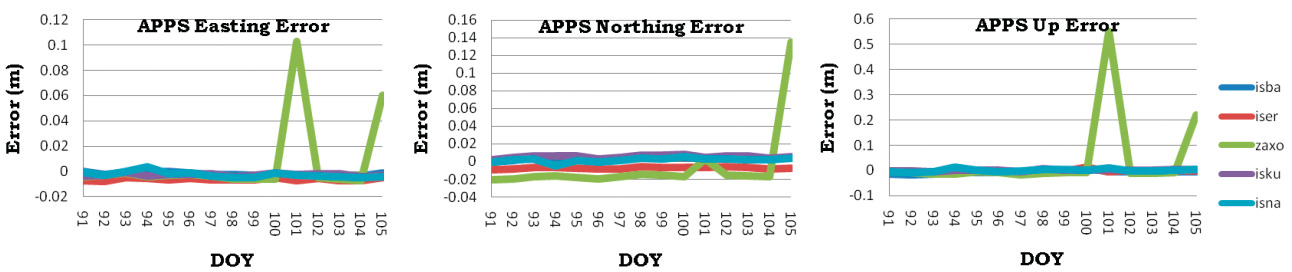

Fig. 2. The difference of reference coordinates from estimated coordinates of APPS
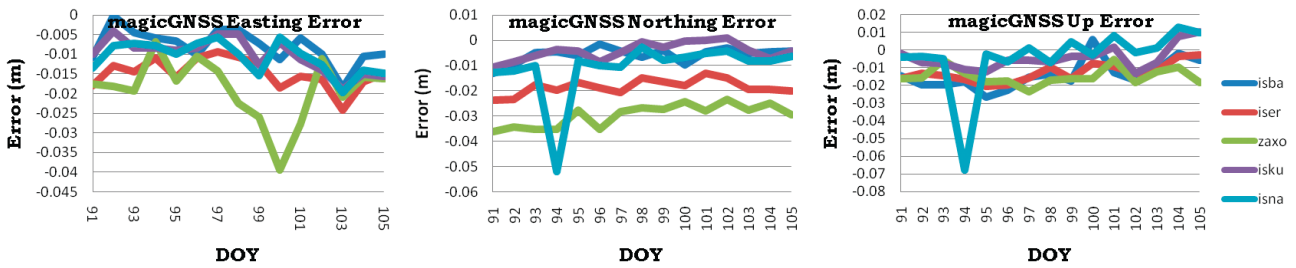

Fig. 3. The difference of reference coordinates from estimated coordinates of magicGNSS

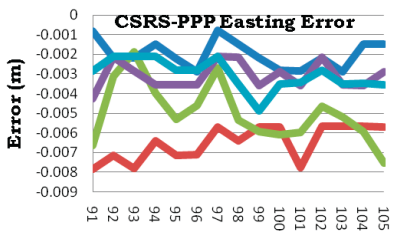

DOY
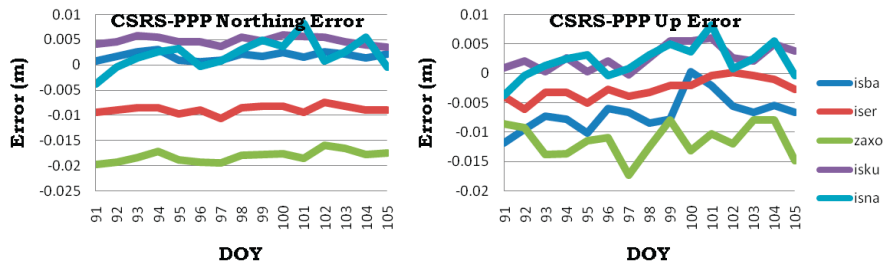

Fig. 4. The difference of reference coordinates from estimated coordinates of CSRS-PPP
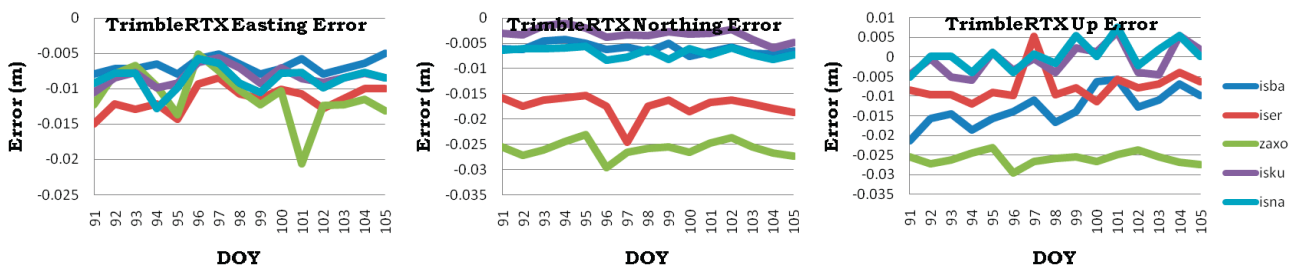

Fig. 5. The difference of reference coordinates from estimated coordinates of Trimble RTX
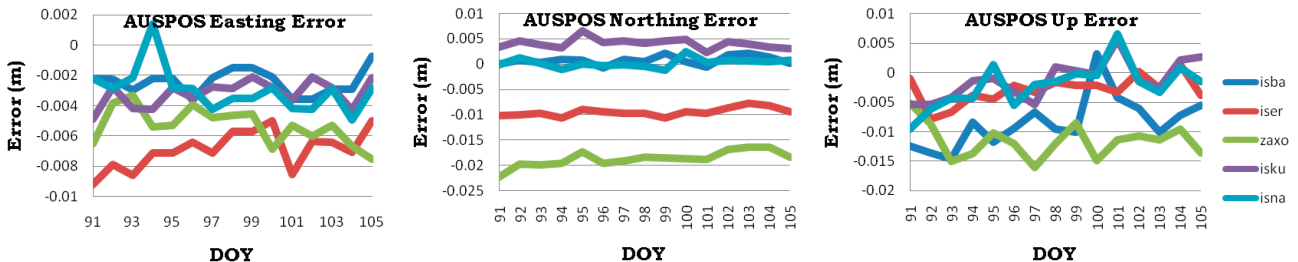

Fig. 6. The difference of reference coordinates from estimated coordinates of AUSPOS 


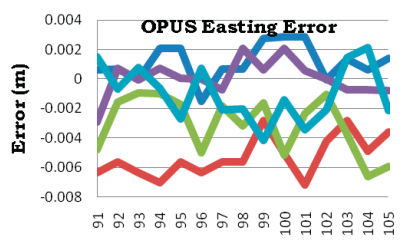

DOY
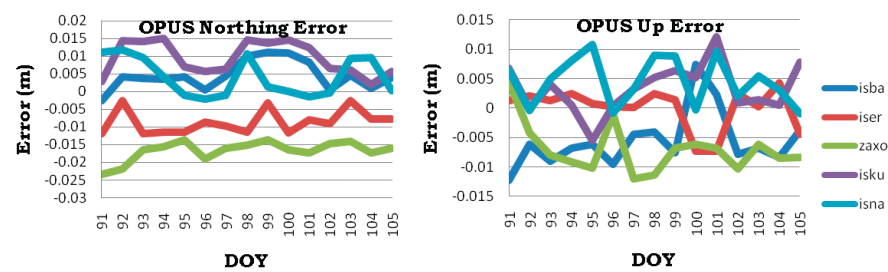

DOY

Fig. 7. The difference of reference coordinates from estimated coordinates of OPUS

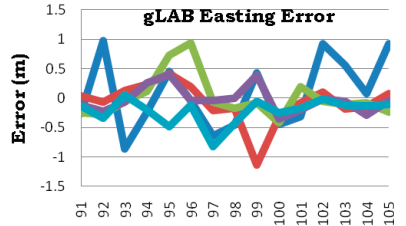

DOY

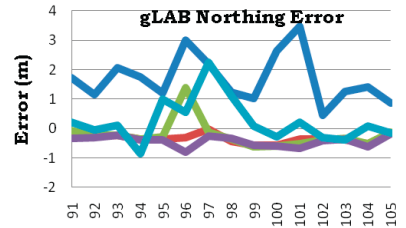

DOY

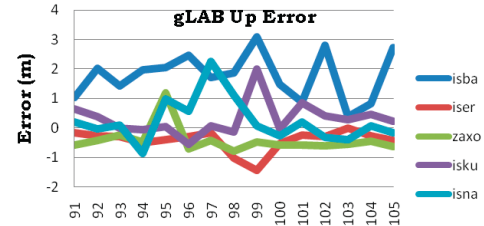

DOY

Fig. 8. The difference of reference coordinates from estimated coordinates of gLAB
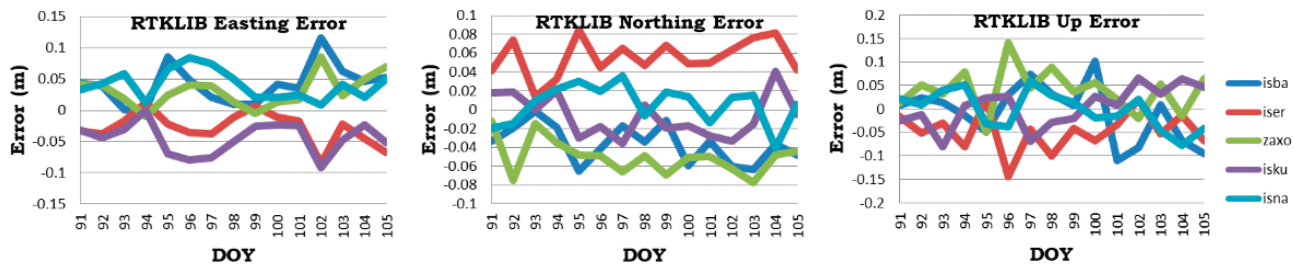

Fig. 9. The difference of reference coordinates from estimated coordinates of RTKLIB

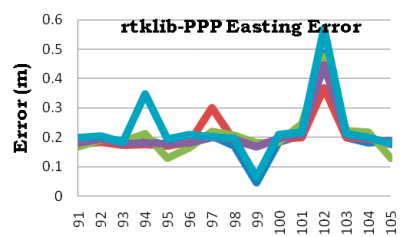

DOY

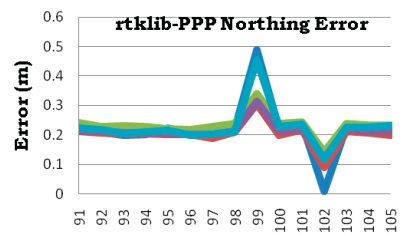

DOY

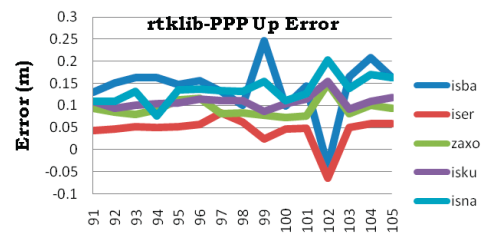

DOY

Fig. 10. The difference of reference coordinates from estimated coordinates of RTKLIB-PPP

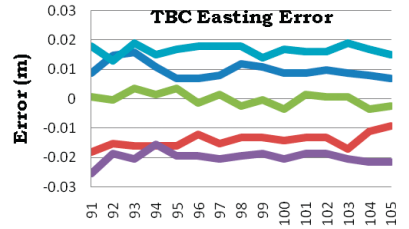

DOY

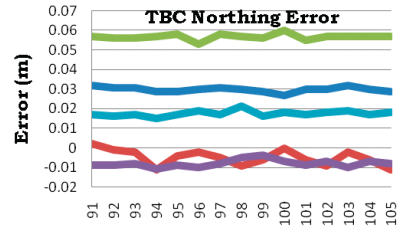

DOY

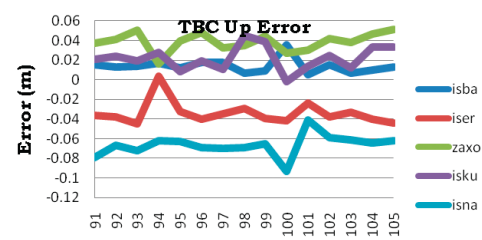

DOY

Fig. 11. The difference of reference coordinates from estimated coordinates of TBC 
From the results in Figures 2-11 and Table 2, the difference in the easting, northing, and UP exceed 1 meter in Figure 8, because when using the same RINEX files uploaded to other online processing services, the gLAB program returned, "solution moved from DGNSS or PPP to SPP due to lack of satellites" so that the solution of gLAB will be excluded from the evaluation and comparison.

Table 2. Final results

\begin{tabular}{|l|c|c|c|c|c|c|}
\hline \multirow{2}{*}{$\begin{array}{c}\text { Processing } \\
\text { method }\end{array}$} & \multicolumn{2}{|c|}{ Horizontal TRMSE $[\mathrm{m}]$} & \multicolumn{3}{c|}{ Vertical TRMSE [m] } \\
\cline { 2 - 7 } & Min. & Mean & Max. & Min. & Mean & Max. \\
\hline \hline APPS & 0.0004 & 0.0188 & 0.1480 & 0.0001 & 0.0525 & 0.5510 \\
\hline AUSPOS & 0.0007 & 0.0086 & 0.0232 & 0.0001 & 0.0063 & 0.0160 \\
\hline CSRS-PPP & 0.0011 & 0.0083 & 0.0208 & 0.0002 & 0.0062 & 0.0173 \\
\hline magicGNSS & 0.0049 & 0.0223 & 0.0526 & 0.0011 & 0.0156 & 0.0678 \\
\hline OPUS & 0.0005 & 0.0099 & 0.0239 & 0.0000 & 0.0059 & 0.0123 \\
\hline TrimbleRTX & 0.0065 & 0.0161 & 0.0322 & 0.0000 & 0.0075 & 0.0213 \\
\hline TBC & 0.0123 & 0.0301 & 0.0600 & 0.002 & 0.0348 & 0.093 \\
\hline RTKLIB-static & 0.0025 & 0.0613 & 0.1307 & 0.0068 & 0.0576 & 0.1440 \\
\hline RTKLIB-PPP & 0.0025 & 0.2967 & 0.5822 & 0.0068 & 0.0947 & 0.2021 \\
\hline gLAB & 0.139918 & 0.9453 & 3.4942 & 0.0104 & 1.0127 & 3.0931 \\
\hline
\end{tabular}

For the processing in the RTKLIB-PPP, the processing settings are in Table 3, the maximum error was $0.58 \mathrm{~m}$ in the easting of DOY 102, the mean error was $0.296 \mathrm{~m}$ which considered high when compared to other processing methods, therefore the processing solutions from RTKLIB-PPP will be not compared with the other solutions.

Table 3. RTKLIB-PPP setting

\begin{tabular}{|c|c|c|c|c||}
\hline $\begin{array}{c}\text { Positioning } \\
\text { mode }\end{array}$ & $\begin{array}{c}\text { Ionosphere } \\
\text { correction }\end{array}$ & $\begin{array}{c}\text { Troposphere } \\
\text { correction }\end{array}$ & Satellite ephemeris/clock & $\begin{array}{c}\text { Integer ambiguity } \\
\text { res. (GPS/GLO) }\end{array}$ \\
\hline \hline PPP static & iono-free LC & estimate ZTD + grad & precise & continuous \\
\hline
\end{tabular}

For the APPS, the accuracy was very high except for a jump in station ZAXO at DOY (101 and 105) that negatively influenced the overall results.

Regarding Table 2 and Figures 2-11, the results show that the differences only in millimeters, which indicates the strength of their algorithms and processes. 
Concerning Figures 12 and 13 and Table 2, the difference between the services and software indicates that the CSRS-PPP had the lowest RMS in the horizontal $(8.3 \mathrm{~mm})$ and vertical $(6.2 \mathrm{~mm})$ directions, followed by AUSPOS and OPUS, the highest range between the maximum and the minimum was recorded by the APPS, it was $0.1476 \mathrm{~m}$ and $0.5509 \mathrm{~m}$ in the horizontal and vertical directions respectively, on the other hand, the lowest range between maximum and the minimum in the horizontal direction was recorded by the CSRS-PPP $0.0197 \mathrm{~m}$, while in the vertical direction was recorded by OPUS $0.0123 \mathrm{~m}$.

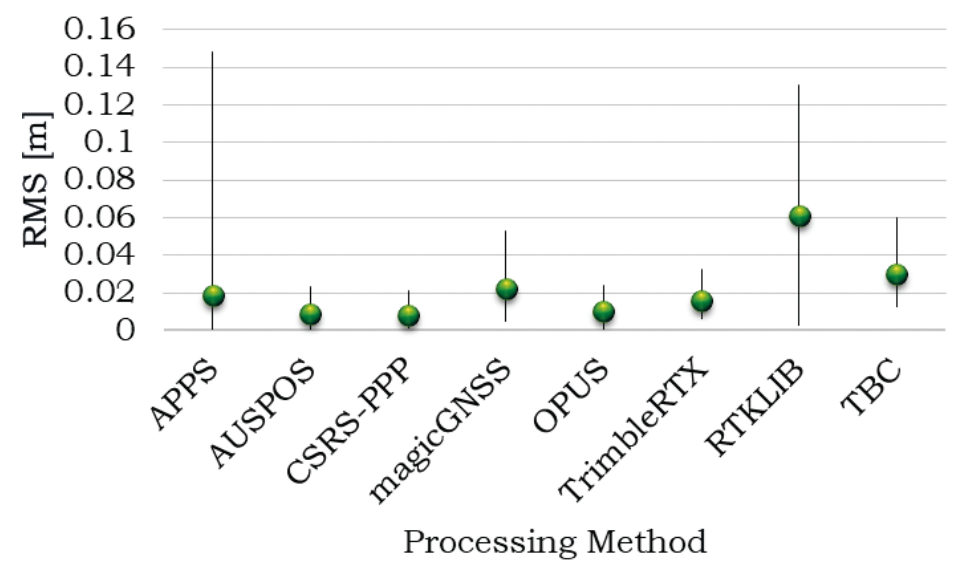

Fig. 12. Horizontal RMS

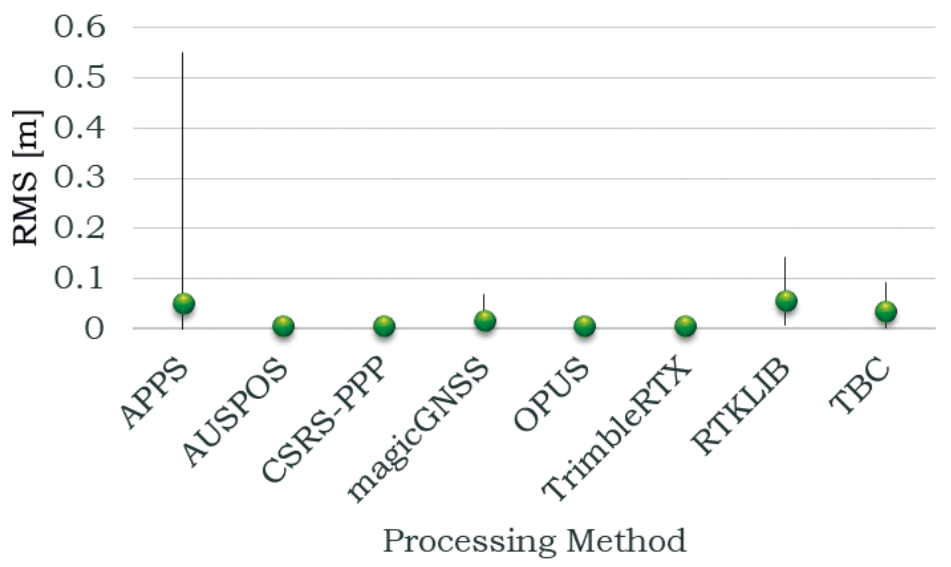

Fig. 13. Vertical RMS

The APPS results in Figure 2, had a jump in the processing of DOYs 101 and 105 at station ZAXO that affected the overall results, which may the results of a thunderstorm that passed over Iraq in days 100 and 101. 
The final processing results indicate that the differences are insignificant for the positioning required for civil engineering projects, it makes sense to use any of them.

\section{Conclusions}

In recent years, online web-based services have become commonly used for GPS data processing. These online web-based services, which analyze GPS data free of charge via the Internet and do not require any prior software knowledge, provide the essential program, hardware, material, personnel, and infrastructure free for users. The quality of such online web-based services is increased through new innovations regarding algorithms for positioning the GPS points and improved accuracy of the products provided by companies (IGS etc.). The online processing services with the free processing software are free and can be used unlimited times.

In this research, a test for online Web services frequently and widely available worldwide to gather with two free processing software RTKLIB and gLAB and the commercial software TBC are evaluated. Five CORS located in Iraq with will known coordinates were used in the assessment.

The GPS data taken into account was 24-hour for 15 days, the results indicate that for precise point positioning services the CSRS-PPP online service has the minimum RMS in the horizontal and vertical direction even when compared to the relative positioning. Taking into account the differences between the CORS coordinates, the best relative positioning is the AUSPOS followed by OPUS, when compared TBC network adjustment and RTKLIB with the web-based online solution, the differences are in centimeters and did not exceed $10 \mathrm{~cm}$.

\section{References}

[1] Al-Kadi I.: GPS Satellite Surveying in Developing Countries - A Review. Journal of King Saud University-Engineering Sciences, vol. 1, no. 2, 1989, pp. 95-109. https://doi.org/10.1016/S1018-3639(18)30863-8.

[2] Albayrak M., Erdoğan B., Erkaya H.: Performance analysis of web-based relative and precise point positioning techniques with different satellite visibility conditions. Boletim de Ciências Geodésicas, vol. 26, no. 1, 2020. https://doi.org/10.1590/ s1982-21702020000100003.

[3] Doucet K., Herwig M., Kipka A., Kreikenbohm P., Landau H., Leandro R., Moessmer M., Pagels C.: Introducing ambiguity resolution in webhosted global multi-GNSS precise positioning with Trimble RTX-PP. [in:] Proceedings of the 25th International Technical Meeting of The Satellite Division of the Institute of Navigation (ION GNSS 2012), vol. 17, no. 21, Institute of Navigation, 2012, pp. 1115-1125. 
[4] Canada.ca: Precise Point Positioning. https://webapp.geod.nrcan.gc.ca/geod/ tools-outils/ppp.php [access: 8.06.2021].

[5] UNB (University of New Brunswick): GAPS. http://gaps.gge.unb.ca/ [access: 8.06.2021].

[6] SOPAC (Scripps Orbit and Permanent Array Center): SCOUT: Scripps Coordinate Update Tool. http://sopac-old.ucsd.edu/scout.shtml [access: 8.06.2021].

[7] JPL (Jet Propulsion Laboratory): The Automatic Precise Positioning Service of the Global Differential GPS (GDGPS) System. https://pppx.gdgps.net/ [access: 8.06.2021].

[8] GMV: MagicGNSS. https://magicgnss.gmv.com/ [access: 8.06.2021].

[9] Trimble: Welcome to Trimble Centerpoint@ Rtx Post-Processing Service. https://trimblertx.com/UploadForm.aspx [access: 8.06.2021].

[10] NOS (National Geodetic Survey): OPUS: Online Positioning User Service. https://geodesy.noaa.gov/OPUS/ [access: 8.06.2021].

[11] Jha M.K., Singh S., Upadhyay N., Khare N.: Comparative Study of Online GPS Post Processing Services and Effects on DGPS Data Processing. International Research Journal of Management Science \& Technology, vol. 7, no. 1, 2016, pp. 29-35.

[12] Schwarz C.R., Snay R.A., Soler T.: Accuracy assessment of the National Geodetic Survey's OPUS-RS utility. GPS Solutions, vol. 13, no. 2, 2009, pp. 119-132. https://doi.org/10.1007/s10291-008-0105-0.

[13] Jia M., Dawson J., Moore M.: AUSPOS: Geoscience Australia's on-line GPS positioning service. [in:] Proceedings of the $27^{\text {th }}$ International Technical Meeting of The Satellite Division of the Institute of Navigation (ION GNSS+ 2014), Institute of Navigation, 2014, pp. 315-320.

[14] Abd-Elazeem M., Farah A., Farrag F.: Assessment study of using online (CSRS) GPS-PPP Service for mapping applications in Egypt. Journal of Geodetic Science, vol. 1, no. 3, 2011, pp. 233-239. https://doi.org/10.2478/v10156-011-0001-3.

[15] Ocalan T.: Accuracy assessment of GPS precise point positioning (PPP) technique using different web-based online services in a forest environment. Šumarski list, vol. 140, no. 7-8, 2016, pp. 357-367. https://doi.org/10.31298/s1.140.7-8.4.

[16] Kong J.-M., Park J.-K., Lee C.-G., Lee Y.-W.: Accuracy analysis of online GPS data processing service. Journal of the Korean Society of Surveying, Geodesy, Photogrammetry Cartography, vol. 28, no. 1, 2010, pp. 13-20.

[17] El Shouny A., Miky Y.: Accuracy assessment of relative and precise point positioning online GPS processing services. Journal of Applied Geodesy, vol. 13, no. 3, 2019, pp. 215-227. https://doi.org/10.1515/jag-2018-0046.

[18] Ghoddousi-Fard R., Dare P.: Online GPS processing services: an initial study. GPS Solutions, vol. 10, no. 1, 2006, pp. 12-20. https://doi.org/10.1007/s10291005-0147-5.

[19] Tétreault P., Kouba J., Héroux P., Legree P.J.G.: CSRS-PPP: an internet service for GPS user access to the Canadian Spatial Reference Frame. vol. 59, no. 1, 2005, pp. 17-28. 
[20] Tobías G., Calle J.D., Navarro P., Rodríguez I., Rodríguez D.: magicGNSS'Real-Time POD and PPP Multi-GNSS Service. [in:] Proceedings of the $27^{\text {th }}$ International Technical Meeting of The Satellite Division of the Institute of Navigation (ION GNSS+ 2014), Institute of Navigation, 2014, pp. 1046-1055.

[21] Canada.ca: Geodetic tools and data. https://www.nrcan.gc.ca/maps-tools-publications/tools/geodetic-reference-systems-tools/tools-applications/10925\#ppp [access: 8.06.2021].

[22] Nardo A., Drescher R., Brandl M., Chen X., Landau H., Rodriguez-Solano C., Seeger S., Weinbach U.: Experiences with trimble CenterPoint RTX with fast convergence. [in:] ESA ENC Conference 2015.

[23] Leandro R., Santos M., Langley R.: GAPS: The GPS analysis and positioning software - a brief overview. [in:] Proceedings of the $20^{\text {th }}$ International Technical Meeting of the Satellite Division of The Institute of Navigation (ION GNSS 2007), Institute of Navigation, 2007, pp. 1807-1811.

[24] Jia M., Dawson J., Moore M.: AUSPOS: Geoscience Australia's on-line GPS Positioning Service. [in:] Proceedings of the $27^{\text {th }}$ International Technical Meeting of The Satellite Division of the Institute of Navigation (ION GNSS+ 2014), Institute of Navigation, 2014, pp. 315-320.

[25] Francis M.G., Ziegler G.: Training Manual for Online Positioning User Service (OPUS). ND Department of Transportation Surveys \& Photogrammetry, 2007. https://www.dot.nd.gov/manuals/design/surveymanual/opus.pdf [access: 8.06.2021].

[26] Hernandez-Pajares M., Juan J., Sanz J., Ramos-Bosch P., Rovira-Garcia A., Salazar D., Ventura-Traveset J., Lopez-Echazarreta C., Hein G.: The ESA/UPC GNSS-Lab tool (gLAB): An advanced multipurpose package for GNSS data processing. [in:] $20105^{\text {th }}$ ESA Workshop on Satellite Navigation Technologies and European Workshop on GNSS Signals and Signal Processing (NAVITEC), 2010, NJ IEEE, Piscataway 2010, pp. 1-8. https://doi.org/10.1109/NAVITEC.2010.5708032.

[27] RTKLIB: An Open Source Program Package for GNSS Positioning. http://www. rtklib.com/ [access: 8.06.2021].

[28] Novikova E., Palamar A., Makhonko S., Barna A., Privalova O.: Transformation parameters between UCS-2000 and WGS-84. Geodesy Cartography, vol. 44, no. 2, 2018, pp. 50-54. https://doi.org/10.3846/gac.2018.1830.

[29] SOPAC/CSRC Archive. http://garner.ucsd.edu [access: 27.08.2021].

[30] Chen Chao Science Network blog. http://blog.sciencenet.cn/blog-8581281203892.html [access: 8.06.2021]. 